\title{
Roda Gigante: Conversa com o escritor
}

Laís Corrêa de Araújo I UFMG

Resumo: Entrevista realizada com Haroldo de Campospara ser publicada na coluna "Roda Gigante", assinada por Laís Corrêa de Araújo, noJornal Estado de Minas, em 13 de agosto de 1961.

Palavras-chave: Entrevista de Haroldo de Campos, Movimento concretista, poesia concreta.

Por ocasião do Congresso de Crítica e História Literária realizado na cidade paulista de Assis, tivemos oportunidade de travar conhecimento com o poeta, pesquisador e tradutor que é Haroldo de Campos, um dos grandes nomes que lideram o movimento concretista em nosso país. Pedimos a Haroldo de Campos que respondesse algumas perguntas para a "Roda Gigante", de forma a esclarecer o leitor mineiro a propósito de sua atitude perante a poesia e outros problemas fundamentais da literatura, cujas respostas - sempre inteligentes e marcadas pela sua acuidade de estudioso e de Poeta sério - transcrevemos a seguir:

- A seu ver, Haroldo, que linha de criação é realmente legítima na atual fase de evolução da poesia e da ficção nacionais?

- Aquela que se propõe à invenção, no plano da evolução de formas. Só a invenção é necessária, pois só ela "produz acréscimo à civilização sob a forma 
de informação", como diria o filósofo da estética Max Bense. Assim, na poesia, uma linha que se poderia traçar desde 22, passando por Drummond a Cabral, até a área de interesses da poesia concreta. Na prosa, uma outra, que não me consta tenha sido freqüentemente traçada, e cujos pontos de referência seriam os romances de Oswald (João Miramar, Serafim Ponte Grande) e de Mário de Andrade (Macunaíma) até Guimarães Rosa (Corpo de Baile, Grande: Sertão Veredas) e, na obra do escritor mineiro, este verdadeiro texto-ápice até o momento que é Meu tio - o Iauaretê).

- Como recebeu a tese do grupo mineiro da revista Tendência, que preconiza a pesquisa de uma expressão literária nacional autônoma?

- Não me parece que a reivindicação nacionalista de Tendência, correta de um ponto-de-vista ideológico, tenha ficado isenta, na sua postulação estética, dos prejuízos de um regionalismo "ingênuo", de tipo temático fechado, que temia os confrontos com as técnicas e os produtos internacionais, talvez porque ainda vítima de um "complexo colonial" residual. Superada, porém, essa fase, creio que se poderá travar com Tendência, um diálogo fecundo. Realmente, acredito que a poesia brasileira (como a arquitetura) esteja em fase de exportação de idéias, em amplo processo de descolonização mental, que já se insinuava desde 22. Ao invés de uma defasagem de uma ou algumas décadas em nossos movimentos literários, já se é possível cogitar de uma vanguarda (como é o caso da poesia concreta) que o é tarnbém para o consumo internacional. Como adverte Guerreiro Ramos ( A Redução Sociológica, 1958) forma-se, em dadas circunstâncias, uma "consciência crítica", que já não mais se satisfaz com a "importação" de objetos culturais acabados", mas cuida de produzir outros objetos nas formas e com as funções adequadas às novas exigências históricas", produção que não é apenas de "coisas", mas também de "idéias". Esse processo é verificável no campo artístico, onde, por exemplo, a poesia concreta operou uma verdadeira "redução estética", com relação às contribuições de determinados autores que, fundamentalmente, elaboravam a linguagem do tempo, totalizando-as e transforrnando-as sob condições brasileiras, no mesmo sentido em que Guerreiro Ramos fala de uma "redução tecnológica", na qual "se registra a compreensão e o domínio do processo de elaboração de um objeto, que permitem uma utilização ativa e criadora da experiência técnica estrangeira”. Daí à exportação o passo é imediato. Lembre-se, finalmente, neste contexto, a frase-lema de Maiacovski: "Sem forma revolucionária não há arte revolucionária". 
Belo Horizonte, p. 1-232

Disponivel em: http://www.letras.ufmg.br/poslit

- Acredita na prevalência da crítica científica como critério de aferição dos fatos literários?

- Acho que a persistência da querela entre crítica científica e crítica impressionista é, no fundo, um pseudo-problema que se radica num equívoco semântico. Há - já o denunciaram os estudiosos da "Semântica geral" - resíduos conceituais na linguagem, de tipo "elementarista", que provêm de cosmovisões superadas, como, por exemplo, as idéias de ESPAÇO E TEMPO, tomadas como entidades distintas, quando a física de hoje não permite conceber senão um ESPAÇOTEMPO. Assim, ao invés de se tomar RACIONALISMO e SENSIBILIDADE como uma correlação diabética - um RACIONALISMO SENSÍVEL seria o caso de dizer - teima-se em se considerar a ambos como unidades estanques. A crítica científica caberia a atitude racionalista e à crítica impressionista a atitude sensível. Ora, nem a critica poderá montar um preciso instrumental metodológico e terminológico que não funcione para verificações práticas ou só o faça em hipóteses despiciendas (como as "máquinas inúteis" da fantasia irônica do escultor Munari), nem se poderá entregar ao borboleteamento irrelevante e desarmado em torno de pretextos que nada tenham a ver com o texto. Deseja-se uma crítica equipada de instrumentos precisos e penetrada de intuição iluminadora, uma crítica, portanto, que valha pela excelência de seus argumentos não EM ABSTRATO, mas testados na prática de sua escolha, nos objetos que ela elege e escrutina.

- Acredita que a chamada "crise de poesia" seja também uma crise do poeta diante do atual estado de coisas no mundo ou apenas uma crise do artesanato do verso?

- "Creio que o relatório-tese de Décio Pignatari - "Situação atual da Poesia no Brasil" - apresentado ao $2^{\circ}$ Congresso Brasileiro de Crítica e História Literária e que logo mais constará dos "Anais" desse certame, juntamente com a transcrição dos debates que suscitou, encerra uma resposta em profundidade a essa pergunta, que aborda um problema fundamental para o poeta de hoje. Assim, remeto-me àquela tese, pois temo esquematizá-la nos percalços de uma simplificação. Avançarei apenas que a "crise do artesanato do verso" nada mais é do que o aspecto estético de uma crise maior - a do artesanato em geral - que se põe no fim do século passado com a 1ํㅡㄹ Revolução Industrial (e hoje já estamos no limiar da $2^{a}$, com a Era da automação!...), crise que, por 
O eixo e a roda: $v .13,2006$

Disponivel em: http://www.letras.ufmg.br/poslit

ser de base, de infraestrutura, tem repercussões necessárias e agudas na superestrutura das idéias.

- Se a solução para essa necessidade de se atualizar o instrumental poético, de modo a conferir à poesia maior funcionalidade em seu processo de comunicação, seria o concretismo, por que o movimento continua restrito a um determinado grupo de poetas e não encontrou ainda a receptividade que era de se esperar?

- É preciso aqui ter bem claras as relações de produção e consumo, precisamente num setor tão específico como a poesia, no qual a clandestinidade não é apenas dos movimentos de vanguarda, mas até de poetas já consagrados, que raramente atingem um grande público, eis que muito constantemente a preferência da burguesia letrada e em melhores condições econômicas deriva para a subliteratura "melodororosa" dos vates de segunda-mão. Como observou há pouco Cassiano Ricardo, com a autenticidade do depoimento de mudos cabos-de-guerra do nosso Modernismo, ainda hoje, "por mais que pareça incrível, há maior auditório para o verso rimado do que para o verso branco, para a arte de rimar do que para a arte de não rimar"...

Por outro lado, o consumo da obra de arte, como salienta Maiakovski num artigo de 1928 ("Os operários e os camponeses não vos compreendem"), em que refuta a pecha de incompreensão lançada por críticos burocratizados contra sua poesia, não é uma coisa dada de antemão, mas o produto da luta do próprio poeta: "A boa acolhida da massa é o resultado de nossa luta e não o efeito de uma camisa mágica na qual nascessem os livros felizes de certos gênios literários. É preciso saber organizar a compreensão de um livro", pois "quanto melhor é o livro, mais ele ultrapassa os acontecimentos". Assim, é preciso distinguir as faixas de consumo: há livros que se destinam primacialmente a produtores (donde se justificar as suas pequenas tiragens iniciais) e que - a comparação é de Maiacovski - são como estação central distribuidora de energia para subestações, livros que acabam inseminando toda a linguagem poética. A poesia concreta alterou substancialmente o contexto da poesia brasileira, gerou dissidências que não deixam de pagarlhe tributo, extrapolou-se do círculo de seus propugnadores iniciais para pôr em situação um número cada vez maior de poetas, jovens ou com obra feita, que denunciam, em suas DEMARCHES pessoais, a presença de muitas das reivindicações do movimento (a sintaxe visual por exemplo, já está hoje 
integrada na linguagem comum de nossa poesia); enfim, invadiu o terreno da visualidade cotidiana, da propaganda, da tipografia, da titulagem dos jornais e dos chamados textos aplicados. Muitos a consumiram sem mesmo o saber e quando estavam mais prevenidos intelectualmente contra ela. Negavam-lhe (e negam-lhe) a etiqueta de "poesia" (que de resto não lhe faz muita falta...), mas entravam (e entram) no circuito de comunicação, consumindo-a como objeto sensível. Que mais se poderia esperar em matéria de receptividade às idéias e produtos de um movimento que tem, como tal, menos de meia década de existência?

- A palavra, em poesia, será "coisa" ou mera "idéia da coisa"?

- Na poesia, a palavra é "coisa", porém não coisa do mundo real, mas do mundo "correal", que é o modo próprio do ser estético, na colocação de Bense. É por isso que Sartre afirma que o poeta "considera as palavras como coisas". Ou que Susanne Langer (via Cassirer) fala, a propósito do fenômeno estético, em "objeto virtual".

- Poderia explicar a diferença de postulados de teoria e criação entre "concretos" e néo-concretos"?

- O crítico Oliveira Bastos, num artigo de 1956 sobre "Vinte e dois e forma", observa que, na poesia brasileira de vanguarda, haviam duas vertentes: uma construtiva e outra destrutiva. Esta colocação permanece exemplar, pois a poesia concreta nada mais é do que a totalização, até as suas últimas conseqüências, de uma idéia de vanguarda construtiva, com projeto, que assume uma responsabilidade total perante a linguagem e pretende ser útil e solidária, enquanto o chamado néo-concretismo (naquilo que tenha de próprio e não seja a mera rotulagem despistadora de experiências que se enquandrem no âmbito do movimento concreto) não é senão a conseqüência última de uma idéia de vanguarda destrutiva, sem projeto, que se demite perante a linguagem em prol de uma extra-linguagem freneticamente subjetiva e hedonista, e que, enfim, cultiva o solipsismo e a solidão. Ao néo-concretismo e ao seu "não-objeto", entendo que cabe à maravilha a crítica de Georges Lukacs ("Le Signification Présente du Réalisme Critique") ao vanguardismo irrealista e decadente de "solitude ontológica". 
O eixo e a roda: $v .13,2006$

Disponivel em: http://www.letras.ufmg.br/poslit

- Que nome destacaria, entre os valores de sua geracão, como realmente capazes de contribuir para a formulação de uma nova poética no Brasil?

- Cito, dentro de minha geração, na área da poesia concreta, Décio Pignatari, Augusto de Campos, José Lino Granewald (- e citaria Ronaldo Azeredo, se não fosse quase dez anos mais moço do que nós todos, pela identificação de seus produtos com o movimento). Fora dela, Mário Faustino, que também já fez entre nós uma eficientíssima crítica militante de poesia, no sentido poundiano-pragmático do termo. Já agora posso acrescentar um poeta mineiro,

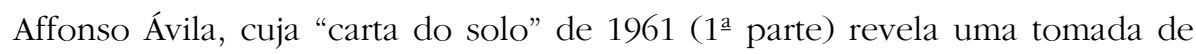
consciência da linha cabralina de nossa poesia e, simultaneamente, das reivindicações da poesia concreta (sobretudo no seu poema "Os Híbridos", para mim o mais representativo da coletânea), constituindo-se assim numa contribuição pessoal e positiva nesse panorama. Affonso Ávila está dando, dentro de sua poesia, o necessário "salto qualitativo". Num sentido correlato, menciono Mario Chomil em algumas de suas novas produções.

Finalmente, não posso deixar de assinalar, quaisquer que sejam as divergências que nos separam, a contribuição de Ferreira Gullar, sobretudo de "A luta corporal" e de alguns poemas na sua primeira linha concreta; creio que Gullar, no momento em que se livrar (se o fizer) dos equívocos do néo-concretismo e do não-objeto, poderá voltar a produzir em bom nível.

- O relatório de Décio Pignatari, apresentado ao Congresso de Crítica e História Literária, pode ser considerado como uma retomada de posição do grupo concretista de São Paulo?

- Não. Trata-se de um relatório dialético que descreve um movimento também dialético. O processo evolutivo desse movimento não pode ser fragmentado em mônadas, nem será compreendido através de uma fixação congelante de momentos. A dialética é feita de fluxos e refluxos, de investidas e recusas. A atual fase da poesia concreta, indicada no relatório, estava já contida no bojo do movimento desde o seu lançamento como projeto. Quando se filou, à certa altura, de "modéstica tática" (1957), já se admitia como natural, após o radicalismo necessário ao domínio e compreensão totais das novas técnicas (sem excluir os êxitos que sem dúvida foram obtidos na produção dessa fase), uma abertura gradual do horizonte semântico, sem abdicação do "ostinato rigore" programado. Quanto ao problema do engajamento, que se 
põe em vários níveis também, desde um engajamento com a linguagem e com a problemática do tempo, até uma participação de caráter propriamente ideológico, é bem de ver que esteve sempre presente em nossos textos e manifestos, para quem os soubesse ler. Lembro, no plano existencial (e ainda na fase pré-concreta), a prática de uma poesia de anti-lirismo, ou de lirismo autêntico, restituído a seu rasgo humano, lawrenciano, direto e anti-"puderie", como profligação das irrealistas fugas metafórico-alienadas de uma poesia de escamoteamento amoroso. Lembro desde o Noigandres 4, de 1958 (poemas de 1957), várias peças de "participação de existência" de "ontologia direta", bem como poemas como "coca-cola" de Décio Pignatari e "petróleo" de J. L. Grunewald (este do livro "um e dois", de 1958), de alistamento evidente. Termino dizendo que o relatório de D. Pignatari conclui dialeticamente, ou seja, problematicamente, sem se propor a uma conciliação paralisante, estatutária, de opostos, mas abrindo-se ao espírito crítico e à aventura criativa.

- Fale um pouco de seus planos e trabalhos no momento. Qual o programa da revista Invenção, que você, e seus companheiros pretendem lançar?

- Planos: publicação da "Teoria da Poesia Concreta", já preparada, provavelmente pela Livraria São José, do Estado da Guanabara, reunindo os textos e manifestos do movimento. Publicação de uma "Antologia de Noigandres", coincidindo com a completação, em 1962, da primeira década de nosso trabalho de equipe, e tendo em vista que nossas edições poéticas, em pequenas tiragens, já estão praticamente esgotadas. Augusto de Campos e eu aguardamos para breve a edição de nosso trabalho conjunto "Panorama", estudo crítico e apresentação de 10 fragmentos de Finnegans Wake de Joyce recriados em português (Ed. Conselho Estadual de Cultura, São Paulo). Preparamos um volume com estudo crítico e antologia do poeta maranhense Sousândrade (1833-1902), cuja reposição em circulação será da maior importância para as nossas letras. Finalmente, eu, em particular, tenho traduções de poetas alemães de vanguarda, de haikaistas e modernos japoneses, de algumas canções de Dante e de poemas de Maiacovski, recriados quase todos a partir do original, para meu livro "Laboratório de Textos". Quanto à revista Invenção, será editada por um grupo de trabalho mais amplo, que inclui não só os concretos Cassiano Ricardo, Mario da Silva Brito, Edgar Braga, Pecdro Xisto, Mário Faustino, Mário Chamie e o crítico Oliveira Bastos, destinando-se à apresentação da obra de arte de vanguarda, não apenas no domínio da 
literatura, mas no da música das artes plásticas, da arquitetura e do cinema, com cobertura nacional e internacional. A crítica e o debate de idéias terão também lugar em Invenção, cujo primeiro número deverá sair em setembro próximo.

(Estado de Minas, Belo Horizonte, 13 ago. 1961)

Abstract: Interview with Haroldo de Campos to be published in the column "Roda Gigante" (Giant Wheel), from The Estado de Minas Journal, signed by Laís Corrêa de Araújo, on August 13th, 1961.

Key words: Interview with Haroldo de Campos, concretist movement, concrete poetry. 